\title{
The clinical course of SARS-CoV-2 positive neonates
}

\author{
Giuseppe De Bernardo $\mathbb{1}^{1} \cdot$ Maurizio Giordano $\mathbb{1}^{2} \cdot$ Giada Zollo ${ }^{1} \cdot$ Fabrizia Chiatto $\mathbb{D}^{3} \cdot$ Desiree Sordino $\mathbb{( I D}^{4} \cdot$ \\ Rita De Santis $\mathbb{1}^{5}$. Serafina Perrone $\mathbb{1}^{6}$
}

Received: 1 May 2020 / Revised: 27 May 2020 / Accepted: 24 June 2020 / Published online: 6 July 2020

(c) The Author(s), under exclusive licence to Springer Nature America, Inc. 2020

\begin{abstract}
The COVID-19 pneumonia was firstly reported in Wuhan, China, in December 2019. The disease had a rapid spread all over the word becoming an international public health emergency. Limited data were available on COVID-19 positive neonates. We reviewed relevant literature to understand the clinical course of disease and transmission routes in affected neonates. The aim of the study was evaluating the clinical course and prognosis of SARS-CoV-2 positive neonates. Based on current literature, the hypothesis of vertical transmission of SARS-CoV-2, though conceivable, remains unproven. A research conducted on PubMed database from December 2019 to April 27, 2020 revealed that were reported 25 neonates affected by SARS-CoV-2. Main symptoms were fever, cough, or shortness of breath but often these neonates did not show other symptoms during length stay in hospital. No deaths occurred.
\end{abstract}

\section{Introduction}

The COVID-19 pneumonia was firstly reported in Wuhan, China, in December 2019. The disease had a rapid spread all over the word becoming an international public health emergency [1]. It was expected that newborns were at high risk for COVID-19-related complications because of their immune characteristics and their physiological changes in cardiovascular and respiratory system at birth [2]. During previous pandemics, they were reported cases of infants suffering from respiratory infection. They were also described cases of spontaneous abortions, preterm delivery,

Giuseppe De Bernardo

pinodebtin@gmail.com

1 Division of Pediatrics Neonatology and NICU, Ospedale Buon Consiglio Fatebenefratelli, Naples, Italy

2 Department of Clinical Medicine and Surgery, Federico II University, Naples, Italy

3 Department of Translational Medical Science, Federico II University, Naples, Italy

4 Department of Emergency, NICU, A.O.R.N. SantobonoPausilipon, Naples, Italy

5 School of Specialization in Pediatrics, Catholic University of the Sacred Heart Faculty of Medicine and Surgery, Rome, Italy

6 Department of Medicine and Surgery, University of Parma, Parma, Italy low birth weight, and birth defects [3, 4]. However, these studies were conducted in a small sample size. Although evidences of SARS-CoV-2 vertical transmission from mothers to foetuses have been described, many doubts remain about the confirmation of vertical transmission [5-7]. The still limited data available on COVID-19positive infants suggest that these patients had benign infections [8], despite concerns about the possibility of being born prematurely and with low birth weight $[9,10]$. Data available for SARS-CoV-2-positive preterm neonates suggest that neonates infected (even if extremely preterm) might not necessarily be susceptible to severe disease with clinically significant or major morbidity [11]. Due to concerns about the possible transmission of this new virus to immunologically naive infants and the absence of definitive studies on this risk, we have reviewed the literature to understand the potential impact of this disease. The aim of the study was evaluating the clinical course, prognosis and transmission routes of the SARSCoV-2-positive newborns.

\section{Methods}

Pubmed database (National Library of Medicine, Washington, DC) was used to search for manuscripts on COVID-19-positive neonates from December 2019 to April 27, 2020. Articles without language limitation describing SARS-CoV-2-positive newborns $\leq 28$ days of 
life, were included. The exclusion criteria were articles reporting infants $>28$ days of life, children and neonates with negative swabs. IgM-positive newborns were excluded if they had negative swabs because there was no conclusive evidence of infection. This result could also be caused by placental alterations allowing the passage of $\operatorname{IgM}$ or false-positive tests [12]. Moreover, it was reported that false-negative and false-positive rate of serum 2019-nCoV IgM were $29.8 \%$ and $3.8 \%$, respectively, while positiveand negative-predictive value were $86.7 \%$ and $91 \%$, respectively [13]. SARS-CoV-2-positive nucleic acid test was considered the gold standard diagnostic tool to confirm the diagnosis with a positive predictive value of $100 \%$ [13]. Research on Pubmed showed 421 papers, of which 345 excluded because they were duplicated, so only 76 articles were considered for analysis. A total of 58 articles were discarded because they met the exclusion criteria and, finally, only 18 articles were considered eligible for review (Table 1).

\section{Data extraction}

The following data were collected for newborns: gestational age, the delivery method, gender, Apgar score, epidemiological history, and comorbidity. Data on the clinical course and outcome of newborns, such as clinical manifestations, transmission route, diagnosis, treatment, length of stay, and mortality were also recorded.

\section{Data synthesis}

Primary outcomes evaluated signs and symptoms of infected newborns, transmission route, treatment, and prognosis.

\section{Results}

Twenty-five SARS-CoV-2-positive newborns were reported (Tables 2 and 3), of which 11 were Chinese (44\%), 3 were Italian (12\%), 2 were Iranian (8\%), and the rest were Spanish or Belgian or Korean (4\%) [11, 12, 14-29]. Caesarean section (CS) occurred in 16 deliveries due to clinical conditions of the mothers $(64 \%)$, and only in 4 cases was chosen vaginal delivery (16\%). Gestational age of the newborns and birth body weight were $37.4 \pm 4$ (range: 26.57-41.28) and 3041.6 $\pm 866 \mathrm{~g}$ (range: 960-4440 g), respectively. In addition, the male-female ratio hospitalized was 2.8, so male infants were more susceptible to SARS-CoV-2 infection than female. Apgar score was greater than 6 and 9 at $1 \mathrm{~min}$ at $5 \mathrm{~min}$, respectively, except in one case of an extremely preterm neonate and another in which the newborn needed neonatal resuscitation $[11,20]$. In $68 \%$ of cases, the mothers were affected by
Table 1 Literature search on Pubmed from December 2019 to April 27, 2020.

\begin{tabular}{llc}
\hline$N$ & Query results & Results \\
\hline 1 & Vertical transmission and Covid19 & 44 \\
2 & Sars-Cov-2 and newborn & 52 \\
3 & Covid19 and newborn & 69 \\
4 & Neonate and Novel Coronavirus & 79 \\
5 & Neonate and Covid19 & 98 \\
6 & Neonate and Sars-Cov-2 & 76 \\
Total manuscripts & 421 \\
Manuscript discarded because duplicates & 345 \\
Manuscripts screened & 76 \\
Manuscripts eligible for the analysis & 18 \\
\hline
\end{tabular}

The screening of the literature revealed 421 results but only 18 articles were eligible for the analysis.

SARS-CoV-2, in 20\% they were affected both mothers and fathers and, in other cases, grandparents were infected. The possibility that third parties may have infected infants cannot be excluded.

\section{Age at presentation and clinical features}

The age disease onset was $8.2 \pm 8.5$ days of life (range: 1-25 days). Clinically, SARS-CoV-2 affected newborns manifested at onset fever $(28 \%)$, vomit $(16 \%)$, cough or shortness of breath $(12 \%)$, diarrhea, lethargy or respiratory difficulty $(8 \%)$ or cyanosis, feeding intolerance, hyperpnea, mild intercostal retractions, mottling, sneezing, nasal stuffiness, paroxysmal episodes (4\%), while only 4/25 newborns were asymptomatic. In the $76 \%$ of cases, newborns did not showed other symptoms during clinical course while in the other cases, it was reported fever $(12 \%)$, cough or vomit $(8 \%)$ and finally diarrhea, hypotension, hypothermia, poor feeding, tachycardia, tachypnoea (4\%). Intensive care was required for $32 \%$ of the newborns, but only a percentage of $20 \%$ was subjected to mechanical ventilation. Major complications were pneumonia $(12 \%)$, respiratory distress $(8 \%)$, and sepsis or pneumothorax $(4 \%)$. They were not reported deaths. Length stay of the newborns was $15.8 \pm$ 10.8 days (range: 5-40 days).

\section{Laboratory and radiologic findings}

Diagnosis of SARS-CoV-2 from admission was obtained at $3.1 \pm 3.4$ days (range: $1-15$ days) mainly by nasopharyngeal swab. In other cases, diagnosis was obtained with samples collected from oropharynx, stool, plasma, urine, or saliva. Data on antibodies were lacking, they were reported only four studies that included immunoglobulin analysis. Buonsenso et al. [28] detected IgG slightly positive in a neonate 


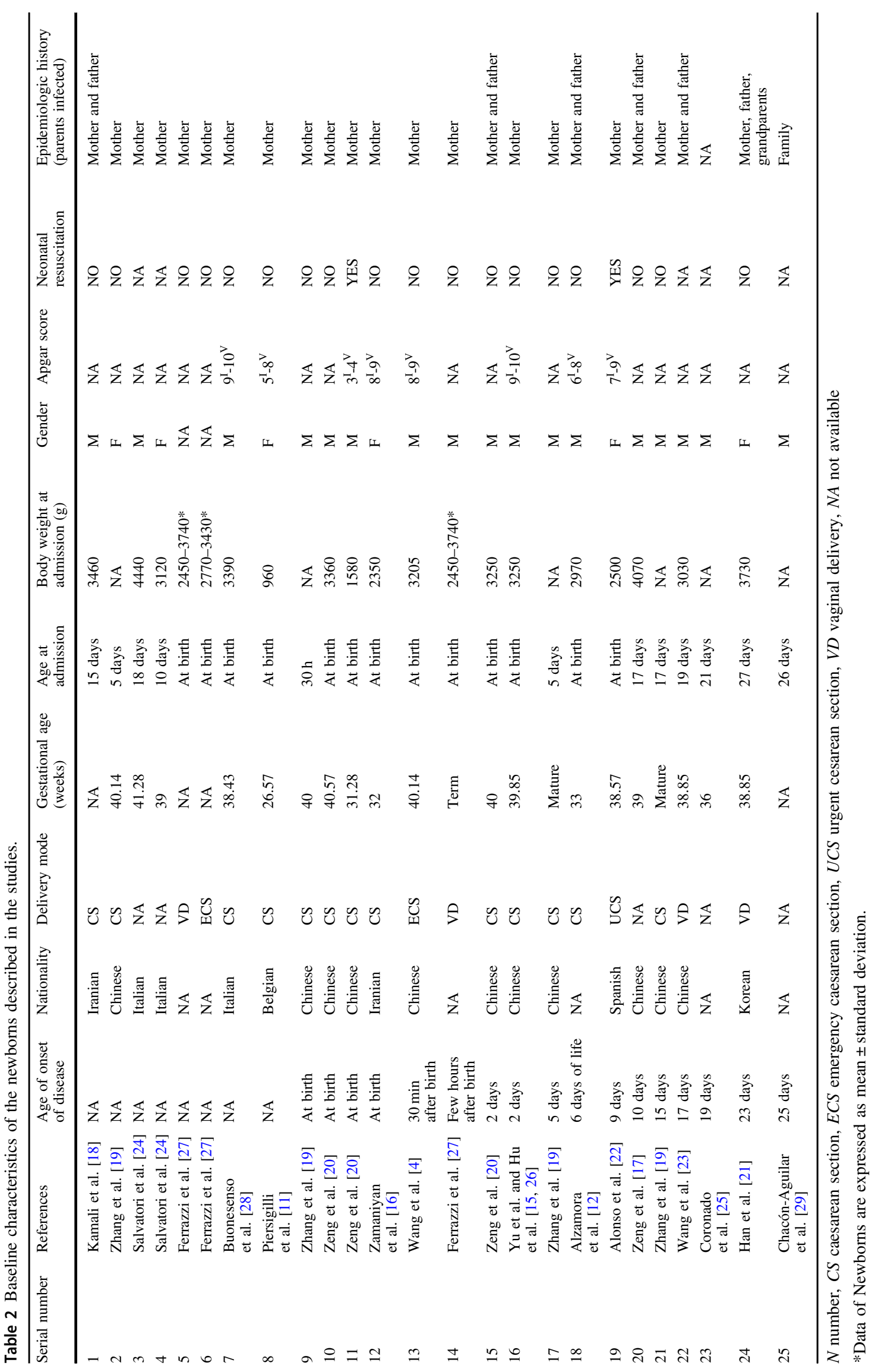




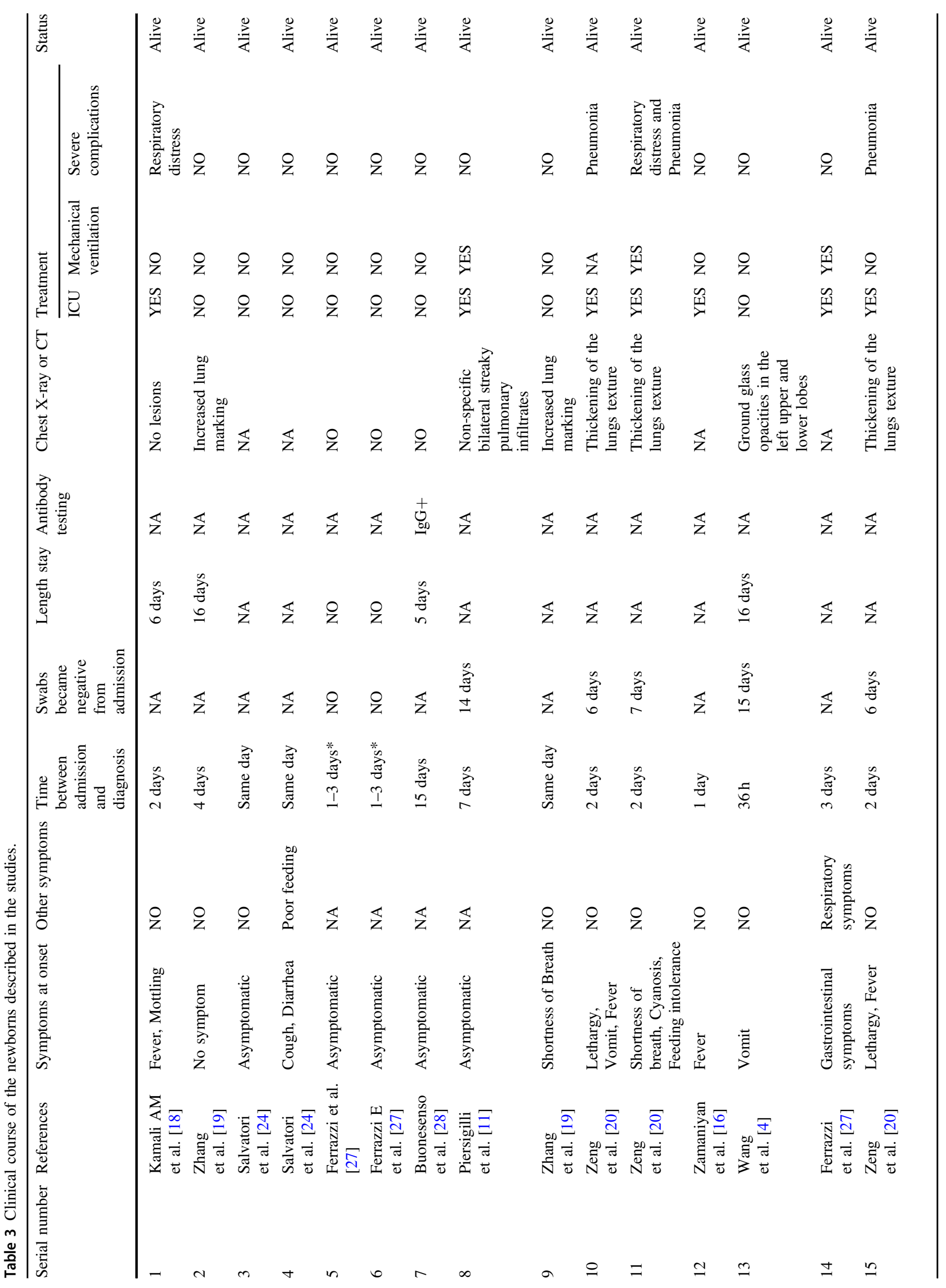




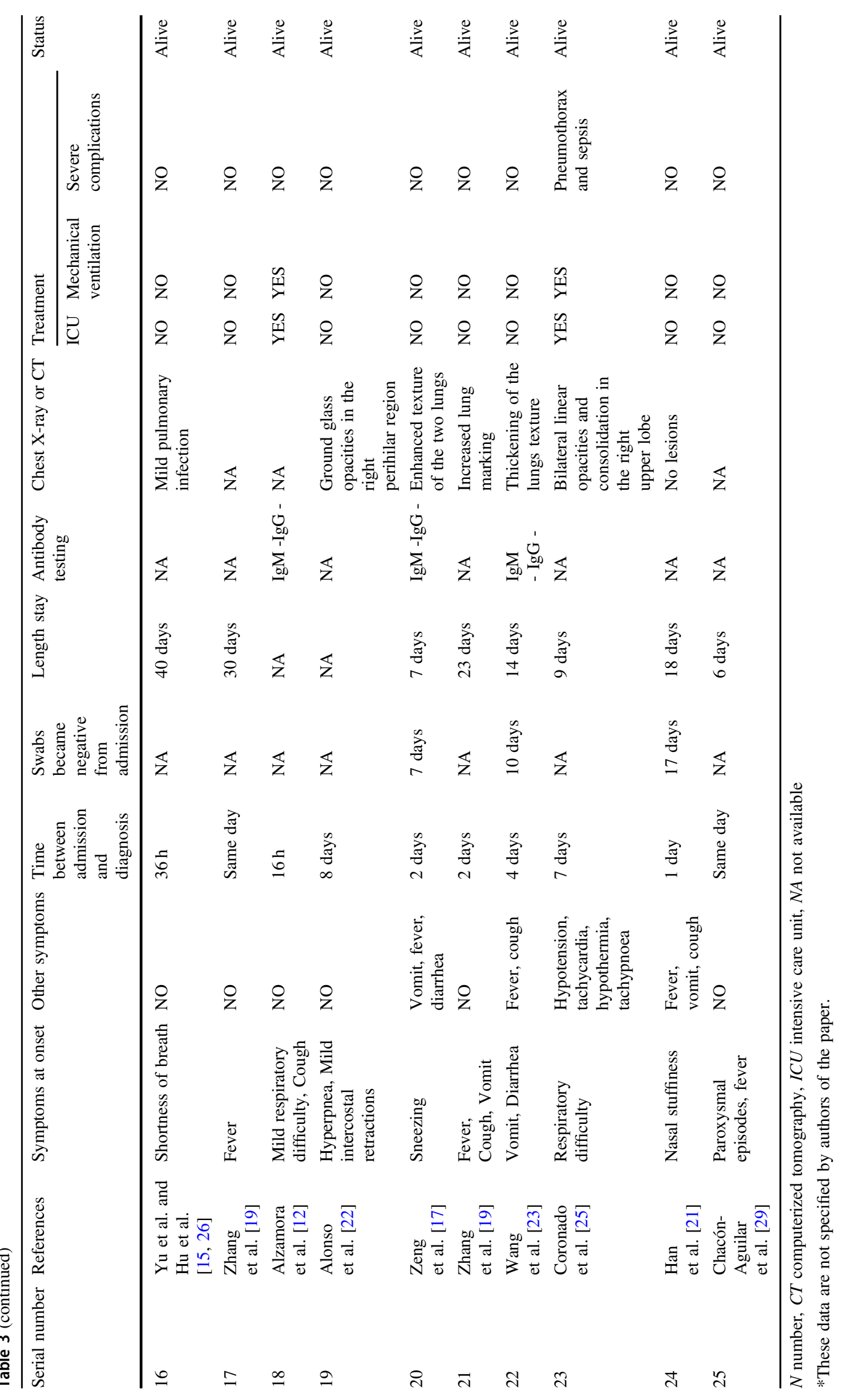


fed by breast milk, his mother was SARS-CoV-2 positive. In the other three case reports, IgM or IgG were negative $[12,17,23]$. The swabs became negative within $10.3 \pm$ 4.5 days (range: $6-17$ days). The radiological study of the lungs of newborns revealed thickening of the lung structure $(32 \%)$, opacity of the ground lobe glass ( $8 \%$ ), and mild lung infection, bilateral linear opacities or bilateral nonspecific striated lung infiltrates (4\%). Lung lesions were not revealed in $48 \%$ of cases, in which fever, cough, diarrhea, patches, vomiting, nasal suffocation, paroxysmal episodes, and poor nutrition were reported.

\section{Discussion}

Current reviews reported clinical course data predominantly on the paediatric population with very few cases of newborns [30-36]. Based on current knowledge, treatment for SARS-CoV-2-positive newborns should be prevalently symptomatic or supportive [32, 33, 37]. After discharge, simple hygiene measures should be taken during home care as caregivers washing hands and face often, disinfecting the daily supplies of newborns with $75 \%$ medical alcohol and chlorine-containing disinfection water to wipe the floor and furniture, regular window ventilation, heat-resistant bottles and pacifiers should be disinfected at high temperature [38]. In Romania, 10 newborns resulted positive to SARS-CoV-2 because healthcare workers did not wear personal protective equipments [39]. However, all newborns were in good conditions and did not show symptoms. The Italian ministry of health reported that in Italy there were about 20-25 SARS-CoV-2-positive newborns but without severe complications [40]. Our data suggest that signs and symptoms of novel coronavirus in newborns could be less serious compared to adults. Main onset symptoms were fever, vomit, cough, or shortness of breath but often these newborns did not show other symptoms during length stay. One of the most difficult questions about COVID-19 in neonates is whether perinatal transmission of SARS-CoV-2 exists. Vertical transmission of infection usually occurs during intrauterine life by placenta, or during delivery by ingestion or aspiration of cervicovaginal secretions, and in the postpartum period by breastfeeding. Parazzini et al. [41] in a review article analysed 13 studies, including 64 women who delivered. Vaginal delivery was reported in six cases. It is recommended to practice reverse transcription polymerase chain reacion (RT-PCR) assay on tissue samples deriving from placenta, amniotic fluid, cord blood, and neonatal pharyngeal swab, to prove that there has been intrauterine viral infection. All these samples should be collected using aseptic technique to prevent contamination [42]. Xu et al. [13] reported that positive-predictive value and specificity of the 2019-nCoV nucleic acid test were
$100 \%$, but negative predictive rate and sensibility were $81 \%$ of $91 \%$, respectively. These data suggest that if $2019-\mathrm{nCoV}$ nucleic acid test give a negative result, it is necessary to repeat the swab to exclude the infection. In the case reported by Wang et al. [14], the pharyngeal swab collected at $36 \mathrm{~h}$ after birth was positive but umbilical cord and placental samples were negative, therefore the vertical transmission of the infection has not been confirmed. In three neonates were detected IgM antibodies in the blood by automated chemiluminescence immunoassays but respiratory swabs were negative for SARS-CoV-2 RNA by RT-PCR. The sensitivity and specificity of this immunoassays have not been extensively evaluated and could give false-positive results [42]. Wang et al. [42] observed that most of the available data concern women infected in the third trimester of pregnancy: in this case, the placental barrier could efficiently prevent the transmission of infection from mother to foetus. Chen et al. [43] collected amniotic fluid and cord blood samples from six COVID-19-positive pregnant mothers and pharyngeal swabs from offsprings: the results of all samples were negative. Lei et al. [44] conducted a similar study on four pregnant women showing similar results. In addition, vaginal secretions were negative for SARS-CoV-2. Chen et al. [45] analysed neonatal pharyngeal swab samples and placental tissues of three pregnant women with COVID-19 but all samples tested negative for SARS-CoV-2 RNA. Therefore, based on current literature the hypothesis of vertical transmission of SARS-CoV-2, though plausible, remains unproven [16, 30, 31, 46-48]. Zamaniyan et al. reported a case of a COVID-19 positive pregnant woman that delivered in severe critical conditions by CS. It was collected $5 \mathrm{ml}$ of amniotic fluid during delivery that resulted positive to SARS-CoV-2, also the nasal-first throat swab of the newborn, obtained at $24 \mathrm{~h}$ of life, was positive to SARS-CoV-2 [16]. This case report shows that in critical conditions, vertical transmission could be possible. On the other hand, they are still unknown the effects of COVID-19 infection in the first or second trimester of pregnancy. Moreover, placental abruption or maternal-foetal haemorrhage as well as placental damage deriving from severe hypoxia in the earliest period of pregnancy in COVID-19-positive women may play an additional role in facilitating vertical transmission. Baud et al. described a case of miscarriage during the second trimester of pregnancy in a SARS-CoV-2-positive mother. The virus was finding in the placenta but not in the foetus maybe for the age of foetal development and short time of maternal infection [49]. Buonsenso et al. [28] reported 7 SARS-CoV-2-positive pregnant mothers but it was revealed the virus in the placental tissue only in one woman whose baby was instead negative. Further studies and longitudinal observation of suspect cases are still needed to solve this challenge. 


\section{Conclusions}

SARS-CoV-2-positive newborns show a good prognosis, with low rate of severe complications and without deaths. Treatments are prevalently symptomatic or supportive. Vertical transmission remains unproven, and horizontal transmission is the most probably source of infection for newborns. Hygiene measures must be always taken during hospital and home care by caregivers. The gap of knowledge will be filled by seroprevalence studies in mothers and newborns. High quality studies are urgently needed about newborns to better understand clinical manifestations, clinical course, and prognosis of SARS-CoV-2-positive newborns.

Author contributions Giuseppe De Bernardo gave substantial contribution to conception and design and revising it critically for important intellectual content. Maurizio Giordano collected the data, carried out the analyses and interpretation of data and reviewed paper critically for important intellectual content. Giada Zollo, Fabrizia Chiatto, Desiree Sordino, Rita De Santis, reviewed the paper critically for important intellectual content. Serafina Perrone supervised data collection, critically reviewed the paper for important intellectual content. All authors approved the final paper as submitted and agree to be accountable for all aspects of the work.

\section{Compliance with ethical standards}

Conflict of interest The authors declare that they have no conflict of interest.

Publisher's note Springer Nature remains neutral with regard to jurisdictional claims in published maps and institutional affiliations.

\section{References}

1. World Health Organization. Coronavirus disease 2019 (COVID19) Situation Report-91. Available from: https://www.who.int/ emergencies/diseases/novel-coronavirus-2019/situation-reports. Cited 27 April 2020.

2. Nicholson EG, Avadhanula V, Ferlic-Stark L, Patel K, Gincoo KE, Piedra PA. The risk of serious bacterial infection in febrile infants 0-90 days of life with a respiratory viral infection. Pediatr Infect Dis J. 2019;38:355-61.

3. Wong SF, Chow KM, Leung TN, Ng WF, Ng TK, Shek CC, et al. Pregnancy and perinatal outcomes of women with severe acute respiratory syndrome. Am J Obstet Gynecol 2004;191:292-7.

4. Alfaraj SH, Al-Tawfiq JA, Memish ZA. Middle East respiratory syndrome coronavirus (MERS-CoV) infection during pregnancy: report of two cases and review of the literature. J Microbiol Immunol Infect. 2019;52:501-3.

5. Li Y, Zhao R, Zheng S, Chen X, Wang J, Sheng X, et al. Lack of vertical transmission of severe acute respiratory syndrome coronavirus 2, China. Emerg Infect Dis. 2020;26:1335-6.

6. Dong L, Tian J, He S, Zhu C, Wang J, Liu C, et al. Possible vertical transmission of SARS-CoV-2 from an infected mother to her newborn. J Am Med Assoc. 2020;26:e204621.

7. Liu H, Wang LL, Zhao SJ, Kwak-Kim J, Mor G, Liao AH. Why are pregnant women susceptible to COVID-19? An immunological viewpoint. J Reprod Immunol 2020;139:103122.
8. Morand A, Fabre A, Minodier P, Boutin A, Vanel N, Bosdure E, et al. COVID-19 virus and children: What do we know? Arch Pediatr 2020;27:117-8.

9. Zhu H, Wang L, Fang C, Peng S, Zhang L, Chang G, et al. Clinical analysis of 10 neonates born to mothers with 2019-nCoV pneumonia. Transl Pediatr. 2020;9:51-60.

10. Chen H, Guo J, Wang C, Luo F, Yu X, Zhang W, et al. Clinical characteristics and intrauterine vertical transmission potential of COVID-19 infection in nine pregnant women: a retrospective review of medical records. Lancet 2020;395:809-15.

11. Piersigilli F, Carkeek K, Hocq C, van Grambezen B, Hubinont C, Chatzis O, et al. COVID-19 in a 26-week preterm neonate. Lancet Child Adolesc Health 2020;S2352-4642:30140-1.

12. Alzamora MC, Paredes T, Caceres D, Webb CM, Valdez LM, La Rosa M. Severe COVID-19 during pregnancy and possible vertical transmission. Am J Perinatol. 2020. https://doi.org/10.1055/s0040-1710050.

13. XuW LiJ, He X, Zhang C, Mei S, Li C, et al. The diagnostic value of joint detection of serum IgM and IgG antibodies to 2019-nCoV in 2019-nCoV infection. Chin J Lab Med. 2020;43:E012.

14. Wang S, Guo L, Chen L, Liu W, Cao Y, Zhang J, et al. A case report of neonatal COVID-19 infection in China. Clin Infect Dis. 2020; ciaa225. https://doi.org/10.1093/cid/ciaa225.

15. Yu N, Li W, Kang Q, Xiong Z, Wang S, Lin X, et al. Clinical features and obstetric and neonatal outcomes of pregnant patients with COVID-19 in Wuhan, China: a retrospective, single-centre, descriptive study. Lancet Infect Dis. 2020;S1473-3099:30176-6.

16. Zamaniyan M, Ebadi A, Aghajanpoor Mir S, Rahmani Z, Haghshenas M, Azizi S. Preterm delivery in pregnant woman with critical COVID-19 pneumonia and vertical transmission. Prenat Diagn. 2020. https://doi.org/10.1002/pd.5713.

17. Zeng LK, Tao XW, Yuan WH, Wang J, Liu X, Liu ZS. First case of neonate with COVID-19 in China. Zhonghua Er Ke Za Zhi. 2020;58:279-80.

18. Kamali Aghdam M, Jafari N, Eftekhari K. Novel coronavirus in a 15-day-old neonate with clinical signs of sepsis, a case report. Infect Dis. 2020;52:427-9.

19. Zhang ZJ, Yu XJ, Fu T, Liu Y, Jiang Y, Yang BX, et al. Novel Coronavirus Infection in Newborn Babies Under 28 Days in China. Eur Respir J. 2020; 2000697. https://doi.org/10.1183/ 13993003.00697-2020.

20. Zeng L, Xia S, Yuan W, Yan K, Xiao F, Shao J, et al. Neonatal early-onset infection with SARS-CoV-2 in 33 neonates born to mothers with COVID-19 in Wuhan, China. JAMA Pediatr. 2020; e200878. https://doi.org/10.1001/jamapediatrics.2020.0878.

21. Han MS, Seong MW, Heo EY, Park JH, Kim N, Shin S, et al. Sequential analysis of viral load in a neonate and her mother infected with SARS-CoV-2. Clin Infect Dis. 2020; ciaa447. https://doi.org/10.1093/cid/ciaa447.

22. Alonso Díaz C, López Maestro M, Moral Pumarega MT, Flores Antón B, Pallás Alonso C. First case of neonatal infection due to SARS-CoV-2 in Spain. Pediatric 2020;S1695-4033:30130-2.

23. Wang J, Wang D, Chen GC, Tao XW, Zeng LK. SARS-CoV-2 infection with gastrointestinal symptoms as the first manifestation in a neonate. Zhongguo Dang Dai Er Ke Za Zhi. 2020;22:211-4.

24. Salvatori G, De Rose DU, Concato C, Alario D, Olivini N, Dotta A et al. Managing COVID-19-positive maternal-infant dyads: an Italian experience. Breastfeed Med. 2020. https://doi.org/10.1089/ bfm.2020.0095.

25. Coronado Munoz A, Nawaratne U, McMann D, Ellsworth M, Meliones J, Boukas K. Late-onset neonatal sepsis in a patient with covid-19. N Engl J Med. 2020. https://doi.org/10.1056/ NEJMc2010614.

26. Hu X, Gao J, Luo X, Feng L, Liu W, Chen J et al. Severe acute respiratory syndrome coronavirus 2 (SARS-CoV-2) vertical transmission in neonates born to mothers with coronavirus disease 
2019 (COVID-19) pneumonia. Obstet Gynecol. 2020. https://doi. org/10.1097/AOG.0000000000003926.

27. Ferrazzi E, Frigerio L, Savasi V, Vergani P, Prefumo F, Barresi S et al. Vaginal delivery in SARS-CoV-2 infected pregnant women in Northern Italy: a retrospective analysis. BJOG. 2020. https:// doi.org/10.1111/1471-0528.16278.

28. Buonsenso D, Costa S, Sanguinetti M, Cattani P, Posteraro B, Marchetti $S$ et al. Neonatal late onset infection with severe acute respiratory syndrome coronavirus 2. Am J Perinatol. 2020. https:// doi.org/10.1055/s-0040-1710541.

29. Chacón-Aguilar R, Osorio-Cámara JM, Sanjurjo-Jimenez I, González-González C, López-Carnero J, Pérez-Moneo-Agapito B COVID19: fever syndrome and neurological symptoms in a neonate. An Pediatr. 2020. https://doi.org/10.1016/j.anpede.2020.04.001.

30. Qiao J. What are the risks of COVID-19 infection in pregnant women? Lancet 2020;395:760-2.

31. Zaigham M, Andersson O. Maternal and perinatal outcomes with COVID-19: a systematic review of 108 pregnancies. Acta Obstet Gynecol Scand. 2020. https://doi.org/10.1111/aogs.13867.

32. Lu Q, Shi Y Coronavirus disease (COVID-19) and neonate: what neonatologist need to know. J Med Virol. 2020. https://doi.org/10. 1002/jmv. 25740 .

33. Ludvigsson JF. Systematic review of COVID-19 in children shows milder cases and a better prognosis than adults. Acta Paediatr. 2020. https://doi.org/10.1111/apa.15270.

34. Yang P, Liu P, Li D, Zhao D. Corona Virus Disease 2019, a growing threat to children? J Infect. 2020. https://doi.org/10.1016/ j.jinf.2020.02.024.

35. Chandrasekharan $\mathrm{P}$, Vento $\mathrm{M}$, Trevisanuto $\mathrm{D}$, Partridge $\mathrm{E}$, Underwood MA, Wiedeman $\mathrm{J}$, et al. Neonatal resuscitation and postresuscitation care of infants born to mothers with suspected or confirmed SARS-CoV-2 infection. Am J Perinatol. 2020. https:// doi.org/10.1055/s-0040-1709688.

36. Elshafeey F, Magdi R, Hindi N, Elshebiny M, Farrag N, Mahdy S et al. A systematic scoping review of COVID-19 during pregnancy and childbirth. Int J Gynaecol Obstet. 2020. https://doi.org/ 10.1002/ijgo.13182.

37. Chen D, Yang H, Cao Y, Cheng W, Duan T, Fan C, et al. Expert consensus for managing pregnant women and neonates born to mothers with suspected or confirmed novel coronavirus (COVID19) infection. Int J Gynaecol Obstet. 2020;149:130-6.

38. Wang SS, Zhou X, Lin XG, Liu YY, Wu JL, Sharifu LM, et al. Experience of clinical management for pregnant women and newborns with novel coronavirus pneumonia in Tongji Hospital, China. Curr Med Sci. 2020;40:285-9.

39. Daily Sabah. 10 newborns contract COVID-19 at Romanian hospital (cited 7 April 2020). Available from: https://www.dailysa bah.com/world/europe/10-newborns-contract-covid-19-at-romania n-hospital.

40. Ministero della Salute. Covid-19, in Italia circa 20 i neonati positivi al virus ma nessuno grave (cited 22 April 2020). Available from: http://www.salute.gov.it/portale/news/p3_2_1_1_1.jsp? lingua $=\mathrm{italiano} \& \mathrm{menu}=$ notizie $\& \mathrm{p}=$ dalministero $\& \mathrm{id}=4560$.

41. Parazzini F, Bortolus R, Mauri PA, Favilli A, Gerli S, Ferrazzi E. Delivery in pregnant women infected with SARS-CoV-2: a fast review. Int J Gynaecol Obstet. 2020. https://doi.org/10.1002/ijgo. 13166.

42. Wang C, Zhou YH, Yang HX, Poon LC. Intrauterine vertical transmission of SARS-CoV-2: what we know so far. Ultrasound Obstet Gynecol. 2020. https://doi.org/10.1002/uog.22045.

43. Chen H, Guo J, Wang C, Luo Fan, Yu Xuechen, Zhang Wei, et al. Clinical characteristics and intrauterine vertical transmission potential of COVID-19 infection in nine pregnant women: a retrospective review of medical records. Lancet. 2020;395:809-15.

44. Lei D, Wang C, Li C, Fang C, Yang W, Cheng B, et al. Clinical characteristics of COVID-19 in pregnancy: analysis of nine cases. Chin. J Perinat Med. 2020;23:225-31.

45. Chen S, Huang B, Luo D, Li X, Yang F, Zhao Y, et al. Pregnant women with new coronavirus infection: a clinical characteristics and placental pathological analysis of three cases. Chin J Pathol. 2020;49:E005.

46. Rasmussen SA, Jamieson DJ. Coronavirus disease 2019 (COVID19) and pregnancy: responding to a rapidly evolving situation. Obstet Gynecol. 2020;135:999-1002.

47. Mimouni F, Lakshminrusimha S, Pearlman SA, Raju T, Gallagher PG, Mendlovic J. Perinatal aspects on the covid-19 pandemic: a practical resource for perinatal-neonatal specialists. J Perinatol. 2020 40:820-6.

48. Peyronnet V, Sibiude J, Deruelle P, Huissoud C, Lescure X, Lucet $\mathrm{JC}$, et al. SARS-CoV-2 infection during pregnancy. Information and proposal of management care. CNGOF. Gynecol Obstet Fertil Senol. 2020;S2468-7189:30110.

49. Baud D, Greub G, Favre G, Gengler C, Jaton K, Dubruc E et al. Second-trimester miscarriage in a pregnant woman with SARSCoV-2 infection. J Am Med Assoc. 2020:e207233. 